\title{
LA CONDICIÓN DE LA UNIVERSIDAD. PENSAMIENTO Y CRÍTICA
}

Al parecer la Universidad es una institución destinada a una existencia problemática.Desde el mismo momento de su aparición, durante la Edad Media, muchas Universidades entraron en serios conflictos con las ciudades en las que estaban instaladas y las reyertas entre estudiantes y ciudadanos llegaron a transformarse a veces en batallas campales. De ahí en adelante se suceden las crisis de organización, de identidad, poder o reconocimiento social. En la historia de la Universidad abundan los problemas derivados de las demandas excesivas, ambiguas o contradictorias del medio externo, de la intervención directa de los poderes poiíticos, de la apertura irrestricta que la llevó a convertirse en centro de agitación al servicio de proyectos de cambio radical de la sociedad, o del cierre frente a toda incitación que viniera desde fuera, con lo cual se transformó en una hermosa e inútil torre de marfii.

Más de una vez, incluso, la Universidad ha estado a punto de desaparecer, al dejar de ser sede de creación del conocimientoy de generación de las grandes revoluciones científicas, como carrió en el siglo XVII.

Hoy vivimos una nueva versión de esta realidad problemática. Ella afecta principalmente y en todo el mundo a las grandes Universidades públicas que, tanto en Europa como en América, se fundaron sobre la base del modelo de las Universidades napoleónica y prusiana, con una doble finalidad: profesional y científica, a la que después se agrega la de extensión o divulgación cultural, como imperativo de la progresiva democratización.

Desde el siglo xviI en adelante, la Universidad se pone al serviciode la modernización y la consolidación de los Estados nacionales, y ese concepto aparece claramente en el disarso fundacional de Andrés Bello, y se reactualiza en los estatutos orgánicos de la Universidad de Chile, principalmente en el de 1931, bajo el cual la institución alcanza el momento de su mayor desarrollo.

Por cta parte, desde que asume la función de Superintenáencia de la Educación, se reconoce a la Universidad de Chile una condición central en la educación y la cultura nacionales. En ese reconocimiento se basa su expansión a todo el territorio nacional y también la entrega de muchas y muy diversas funciones.

Hoy, cuando ya no hay un centro de casi nada, cuando el Estadotiende a volatilizarse, cuando la información $\boldsymbol{s}$ escurre libremente por redes 
electrónicas, y cuando lo fáctico diluye al proyecto o al diseño social, necesariamente hay que volver a pensar o a plantearse en términos le problema cuestiones como el lugar que ocupa la Universidad en los nuevos escenarios de generación y difusión del conocimiento, o cuáles son o deberían ser sus relaciones con el Estado y con la sociedad; conviene preguntarse, por ejemplo, cuál es la mejor organización para el estudio de áreas que no caben en ninguna de las Facultades tradicionales, o qué sentido tienen las disciplinas humanistas.

El Comité Editor de los "Anales de la Universidad de Chile" advirtió la necesidad de esta reflexión y de este diálogo, e invitó a un grupo de profesores e intelectualesde la Corporación,y de fuera de ella, a preparar los textos que ahora entregamos en esta sección.

En el valioso afán por recuperar los diversos componentes de una institucionalidad que históricamente se ha inscritoe n el desenvolvimientodel país, la Vicerrectoría Académica y Estudiantil convocó, a un número representativo de académicos, a compartir el proyecto de la nueva serie - de los "Analesde la Universidad de Chile". Tarea no exenta de complejidad dado el problema de una situación cultural inédita que trae consigo la consecuente ambigüedad de inscripción de cualquier actividad institucionai. Por mismo, los "Analesde la Universidad de Chile"no podían ya entenderse como continuidad de su formulación interrumpida y exigían preguntarse por la razón misma de su reedición.

Así se concluyó en la necesidad de una publicación de carácter monográfico, dedicada a atender los problemas contextuales más significativos. En coherencia con lo anterior surgióel acuerdo unánime en cuanto a que sólo seríamos capaces de satisfacerel desafío propuesto, si antes asumíamos la responsabilidad de interrogamos por la situación actual de la misma Universidad; esto significaba, primero, dirigirnos a los propios universitarios.Lo que a su vez determinó, en el diseño general, la decisión de dedicar los dos primeros números a esta indagación. Propósito entonces de búsqueda, al interior del propio cuerpo académico, de un pensamiento latente, o actitud deseante, capaz de virtualizar un concepto de Universidad en cuanto la nueva situación.

En el mejor logro de este objetivo se vio la necesidad de una convocatoria capaz de cubrir la máxima heterogeneidad, incluida la generacional, y también la de invitar a académicos o personalidades culturales ajenas a la Universidad de Chile, Podríamos definir esto como la importancia de enfrentarnos a la imagen externa de la Universidad, arriesgando allí, por supuesto, la confrontación crítica. 